\title{
Boas Práticas para Redução da Emissão de Material Particulado Proveniente dos Canteiros de Obras
}

\author{
Ingrid Priscylla Silva Araújo \\ Rita Jane Brito de Moraes \\ Dayana Bastos Costa
}

\section{Introdução}

Uma construção é composta de uma série de operações e atividades diferentes, cada uma com um tempo de duração próprio e uma geração potencial de material particulado (MP). A emissão de material particulado tem uma origem definida e um destino que pode variar substancialmente em fases diferentes do processo de construção, tais como: demolição, terraplanagem, superestruturas, vedações e acabamento (MUÑOZ, PALACIOS, 2001; RESENDE, 2007).

Na construção civil, em especial durante a execução da obra, diariamente ocorre geração de poeira. O mecanismo de emissão dessa poeira está relacionado à ação dos ventos que atuam durante a realização de atividades, como a mistura e a subdivisão de diversas matérias primas de diferentes granulometrias, tais como: areia, cimento, cal, gesso, argamassas, madeira, cerâmica, granito, aço, entre outras. Ademais, por meio de suas atividades construtivas, por exemplo: fabricação de concreto e argamassa, jateamento de argamassa, corte de aço, de madeira, de cerâmica ou de granito, aplicação de gesso, varrição a seco, lixamento de superfícies, escavações, estocagem 
de pilhas de materiais ao ar livre, movimentação nas vias de tráfego, especialmente as não pavimentadas, ou de veículos e equipamentos movidos à combustão, entre outras atividades geradoras de diversos tipos de poeiras, que se propagam no ambiente de trabalho e na vizinhança da construção (ENVIRONMENT AGENCY, 2004; RESENDE, 2007; RESENDE, CARDOSO, 2007; MARTINS, 2009).

Neste sentido, as obras de construção civil representam fontes significativas de partículas com diversas composições para a atmosfera, causando sérios incômodos aos trabalhadores e à vizinhança das edificações. Essas emissões na maioria das vezes não podem ser confinadas, o que dificulta o seu controle. Contudo, boas práticas são conhecidas e disponíveis para a redução dessas emissões.

Este capítulo apresenta orientações para o desenvolvimento de um plano de gestão da emissão do material particulado da obra, destacando a fontes de MP provenientes do canteiro de obra e as atuais boas práticas para controle de poeira e partículas geradas pelas atividades de construção civil.

\section{Padrões de Qualidade do Ar}

Material particulado é definido como um conjunto de poeiras, fumaças e todo tipo de material sólido ou líquido que se mantém suspenso na atmosfera em decorrência de seu pequeno tamanho (CETESB, 2004). Essas partículas são classificadas de diferentes formas, dentre as quais se destacam as Partículas Totais em Suspensão (PTS), as Partículas Inaláveis (MP10) e as Partículas Inaláveis finas (MP2,5).

As Partículas Totais em Suspensão (PTS) são aquelas cujo diâmetro aerodinâmico é menor que $50 \mu \mathrm{m}$. Uma parte dessas partículas é inalável e pode causar problemas à saúde, a outra pode prejudicar a qualidade de vida da população, interferindo nas condições estéticas do ambiente e prejudicando as atividades normais da comunidade. Já as Partículas Inaláveis (MP10) são aquelas cujo diâmetro aerodinâmico é menor que $10 \mu \mathrm{m}$, dependendo da distribuição de tamanho na faixa de 0 a $10 \mu \mathrm{m}$. Podem ficar retidas na parte superior do sistema respiratório ou penetrar profundamente, alcançando os alvéolos pulmonares. Por fim, as Partículas Inaláveis finas (MP2,5), também denominadas Partículas Respiráveis, são aquelas cujo diâmetro aerodinâmico é menor que $2,5 \mu \mathrm{m}$, e devido ao seu tamanho diminuto, penetram profundamente no sistema respiratório, podendo atingir os alvéolos pulmonares, CETESB (2004).

Os padrões de qualidade do ar são valores de referência para diferenciar uma atmosfera poluída de uma não poluída. No Brasil, os padrões de qualidade do ar e episódios críticos de poluição foram estabelecidos pela Resolução CONAMA no 03 de 1990 (CONAMA, 1990) e ainda hoje estão em vigor (Tabela 1), porém permanecem desatualizados em face dos novos conhecimentos científicos, especialmente aqueles 
reconhecidos pela Organização Mundial da Saúde - OMS (PACYNA, 2005). Soma-se a isso, o fato de as metas propostas pela OMS serem mais restritivas se comparadas a alguns padrões adotados no mundo, inclusive os brasileiros (Tabela 2).

Tabela 1 - Padrões Nacionais de Qualidade do Ar (Resolução CONAMA no 03, 1990).

\begin{tabular}{|c|c|c|c|c|}
\hline Poluentes & $\begin{array}{l}\text { Tempo de } \\
\text { amostragem }\end{array}$ & $\begin{array}{l}\text { Padrões } \\
\text { Primários } \mu \mathrm{g} / \mathrm{m}^{3}\end{array}$ & $\begin{array}{l}\text { Padrões } \\
\text { Secundários } \mu \mathrm{g} / \mathrm{m}^{3}\end{array}$ & $\begin{array}{l}\text { Método de } \\
\text { medição }\end{array}$ \\
\hline $\begin{array}{l}\text { Partículas Totais } \\
\text { em Suspensão }\end{array}$ & $\begin{array}{l}24 \text { horas }^{(1)} \\
\text { mga }^{(2)}\end{array}$ & $\begin{array}{l}240 \\
80\end{array}$ & $\begin{array}{l}150 \\
60\end{array}$ & $\begin{array}{l}\text { Amostrador de } \\
\text { Grande Volume }\end{array}$ \\
\hline $\begin{array}{l}\text { Partículas } \\
\text { Inaláveis (MP10) }\end{array}$ & $\begin{array}{l}24 \operatorname{horas}^{(1)} \\
\operatorname{maa}^{(3)}\end{array}$ & $\begin{array}{l}150 \\
50\end{array}$ & $\begin{array}{l}150 \\
50\end{array}$ & $\begin{array}{l}\text { Separação } \\
\text { Inercial/ Filtração }\end{array}$ \\
\hline
\end{tabular}

Fonte: CETESB, 2004.

${ }^{1}$ Não deve ser excedido mais de uma vez ao ano.

${ }^{2}$ Média geométrica anual.

${ }^{3}$ Média aritmética anual.

O padrão brasileiro para o MP10 estabelece concentração média anual de $50 \mu \mathrm{g} / \mathrm{m}^{3}$, embora o ideal, segundo a OMS, seja de $20 \mu \mathrm{g} / \mathrm{m}^{3}$. Para concentração de MP10 em 24 horas, o padrão nacional é de $150 \mu \mathrm{g} / \mathrm{m}^{3}$, enquanto a OMS estabelece o valor de concentração máximo de $50 \mu \mathrm{g} / \mathrm{m}^{3}$.

Tabela 2 - Critérios de Qualidade do Ar adotados no mundo.

\begin{tabular}{lllll}
\hline $\begin{array}{l}\text { País/Poluente - } \\
\text { Padrão }\end{array}$ & $\begin{array}{l}\text { MP2,5 } \\
\text { Padrão Primário }\end{array}$ & $\begin{array}{l}\text { MP10 } \\
\text { Padrão Primário }\end{array}$ & $\begin{array}{l}\text { Tempo de } \\
\text { amostragem }\end{array}$ & \\
\hline \multirow{2}{*}{ OMS } & 10 & 20 & Fonte \\
& 25 & 50 & Anual & PACYNA (2005) \\
\multirow{2}{*}{ EUA } & 15 & Revogado & Anual & US EPA (2006) \\
& 35 & 150 & 24 horas & \\
\multirow{2}{*}{ REINO UNIDO } & 25 & 40 & Anual & Environmental \\
& - & 50 & 24 horas & Protection (2010) \\
\hline
\end{tabular}

Fonte: Adaptado de Pacyna, 2005; USEPA, 2006 e Environmental Protection 2010.

A legislação brasileira não leva em consideração o canteiro de obra como fonte geradora de resíduos para estabelecer padrões de qualidade do ar, tampouco considera a composição química dos materiais gerados, levando apenas em conta a concentração das partículas em termos de massa, o que pode representar um risco potencial tóxico significante. 


\section{Medição de Material Particulado na Construção}

Embora haja o reconhecimento de que a atividade de construção civil constitui uma importante fonte de emissão de material particulado, até recentemente, poucas pesquisas haviam sido direcionadas à caracterização desse tipo de resíduo (MULESKI et al., 2005).

De acordo com Countess Environmental (2006), Resende (2007) e California Natural Resources Agency Guide (CEQA, 2009), as emissões geradas a partir de atividades de construção comuns incluem:

a) Emissões de escape de material particulado (MP) e óxidos de nitrogênio (NOX) oriundos da queima de combustíveis de veículos pesados a diesel e equipamentos movidos à gasolina, equipamento auxiliar portátil, caminhões de entrega de material e de viagens diárias de troca de trabalhadores;

b) Poeira de MP fugitiva (proveniente de atividades não fixas) geradas pela movimentação de solo e da atividade de demolição, limpeza e estocagem, perfuração, serragem, produção de concretos e argamassas;

c) Emissões por evaporação de gases orgânicos reativos, compostos orgânicos voláteis (COV) derivados de atividade e da aplicação de revestimentos arquitetônicos de pavimentação. A aplicação de revestimentos arquitetônicos normalmente é uma das maiores fontes de emissões ROG (Reactive Organic Gases) ou COV durante a atividade de construção;

d) Emissões de escape de gases de efeito estufa (GEE), como o dióxido de carbono $\left(\mathrm{CO}_{2}\right)$, metano $\left(\mathrm{CH}_{4}\right)$ e óxido nitroso $\left(\mathrm{N}_{2} \mathrm{O}\right)$.

No caso específico do canteiro de obras, o material particulado é constituído de pó de cimento, gesso, cal, argamassa industrializada, poeira do solo, entre outros (RESENDE, 2007). As emissões secundárias (emissões não relacionadas diretamente às atividades de construção), apesar de não tão significativas, devem ser consideradas na elaboração de estratégias de redução do impacto ambiental no canteiro de obras, como é o caso das emissões de gases provenientes da queima de combustíveis de veículos e da queima de madeira (RESENDE, 2007). Não só as atividades de construção devem ser consideradas, mas também as emissões dos veículos em estrada associadas com o local de construção.

Recentemente, foram desenvolvidas pesquisas no âmbito do subprojeto SPEMP acerca da medição da concentração de material particulado provenientes de canteiro de obras (ARAÚJO, 2014; ARAÚJO, COSTA, MORAES, 2014; MORAES, 2015; MORAES, COSTA, ARAÚJO, 2016), com o objetivo de identificar as fases da construção e atividades potenciais geradoras de material particulado, bem como suas concentrações (MP2,5; MP10 e PTS). 
Tais estudos experimentais foram desenvolvidos em cinco canteiros de obras habitacionais, localizados em Salvador na Bahia, sendo aplicado em apenas um deles algumas das boas práticas para a redução da emissão de material particulado, ao passo que em quatro dos canteiros não se utilizou nenhuma boa prática para minimização dessas emissões e redução dos impactos para a vizinhança das obras. Os estudos foram desenvolvidos em fases distintas da obra, como a terraplanagem, a superestrutura e o acabamento.

Os principais resultados dessas pesquisas evidenciaram que os canteiros de obra lançam, no ambiente, partículas de vários tamanhos. O perfil apresentado demonstra que as frações MP10 e MP2,5 estão numa faixa de 40\% e 17\%, respectivamente, da fração PTS (ARAÚJO, COSTA, MORAES, 2014). Como as frações maiores (PTS e MP10) tendem a permanecer menor tempo no ambiente, uma vez que se sedimentam mais rápido, elas causam os maiores incômodos na vizinhança, além de representarem o maior percentual emitido pelos canteiros (ARAÚJO, COSTA, MORAES, 2014).

De acordo com o estudo de Moraes (2015), foram encontradas as seguintes faixas de valores mínimos para as frações PTS, num intervalo de 350 a $40 \mu \mathrm{g} / \mathrm{m}^{3}$ e valores máximos de 700 a $150 \mu \mathrm{g} / \mathrm{m}^{3}$. Para a fração MP10 a faixa de valores mínimos obtidos foi de 150 a $20 \mu \mathrm{g} / \mathrm{m}^{3}$ e os valores máximos de 280 a $50 \mathrm{\mu g} / \mathrm{m}^{3}$ em um período de 8 horas diárias (MORAES, 2015). Esses dados não podem ser diretamente comparáveis aos valores de referência da OMS ou da resolução CONANA n 3 , pois os padrões normativos são para um período de 24h. Entretanto, observa-se que, mesmo para 8 horas de medição no período de atividade do canteiro, reconhecendo as contribuições de emissões externas, por vezes, estes limites foram superiores a legislação nacional e a OMS.

A análise química das amostras da fração MP10 que foram coletadas na entrada e na saída dos canteiros estudados mostrou claramente a contribuição dos canteiros e a constituição do material gerado, tendo-se como principais elementos químicos identificados, que fazem parte dos materiais de construção, o Si (Silício), Ca (Cálcio), Fe (Ferro), Al (Alumínio), S (Enxofre) e K (Potássio) (MORAES, COSTA, ARAÚJO, 2016).

\section{Gestão e Monitoramento do MP em Canteiro de Obras}

Para realizar a gestão de MP, é necessário que sejam seguidos alguns princípios capazes de ajudar a estruturar um "plano de gestão" (RESENDE, 2007). O ciclo PDCA ou ciclo de Deming é frequentemente utilizado para estruturar sistemas de gestão (RESENDE, 2007). Segundo Resende (2007), um sistema de gestão deve estar baseado em quatro etapas fundamentais: 
I. Planejamento (P - planning) - estabelece objetivos e metas, processos e metodologias para se obter o resultado esperado;

II. Execução $(D-d o)$ - consiste em colocar em prática o planejado;

III. Verificação/controle ( $\mathrm{C}$ - check)- monitorar e avaliar periodicamente resultados, avaliar metodologias, confrontar com o inicialmente planejado;

IV. Ação (A - act) - de acordo com o encontrado nas atividades de verificação e controle, tomar ações para melhoria imediata ou de processos futuros.

O Quadro 1 apresenta algumas medidas para um plano de gestão de MP.

A aplicação sucessiva desses passos aumenta as possibilidades de que a gestão de um determinado processo ou de um conjunto de processos tenha sua eficiência melhorada (RESENDE, 2007). De qualquer modo, cada canteiro tem suas particularidades, portanto, em cada uma das etapas, devem ser propostas medidas específicas para atender com eficiência os objetivos do plano de ação.

Quadro 1 - Sugestão de ações para plano de gestão.

\begin{tabular}{|l|l|l|}
\hline Planejamento & Implementação e Operação & Verificação e Ação corretiva \\
\hline - Iniciação da fase de & - Integração - iniciação & - Verificação do grau de risco; \\
planejamento; & execução; & -Verificação das atividades \\
- Avaliação de grau de risco e & - Definição de & geradoras correntes; \\
estimativa de emissões; & responsabilidades; & - Verificação dos \\
- Verificação de aspectos & - Contratações; & procedimentos de \\
legais; & - Treinamentos internos e & monitoramento; \\
- Apoio à concepção projetos & externos; & - Verificação da eficácia das \\
e planejamento de & - Comunicações internas e & atividades de prevenção, \\
execução; & com vizinhança. & controle e monitoramento; \\
-Identificação das atividades & & - Verificação dos \\
emissoras de MP, & & equipamentos de \\
procedimentos de controle; & & monitoramento; \\
- Elaboração dos & & - Verificação de treinamentos \\
procedimentos de controle; & & e planos de comunicação; \\
- Plano de monitoramento; & & - Planos de ações corretivas e \\
- Avaliação de custos e & & emergenciais; \\
prazos; & & - Encerramento - término da \\
- Definição de & & execução. \\
responsabilidades; & & \\
- Plano de comunicação; & & \\
- Requisitos para & & \\
contratações; & & \\
-Encerramento da etapa de & & \\
planejamento. & & \\
\hline
\end{tabular}

Fonte: Resende e Cardoso, 2007. 
Além do planejamento, o controle das emissões de material particulado depende de uma transferência adequada dessas informações às equipes de produção e de um controle contínuo para sua aplicação (RESENDE; CARDOSO, 2007).

\section{Fontes de emissão e boas práticas para redução da emissão de material particulado}

Como já mencionado, devido ao desprendimento de MP ao longo das atividades de construção, que afetam os trabalhadores, os animais, as plantas, a vizinhança, entre outros, faz-se necessário adotar medidas de controle, a partir da utilização de equipamentos e atividades adequadas, a fim de mitigar a emissão desses resíduos de acordo com as atividades construtivas, bem como priorizar os cuidados necessários dentro do canteiro de obra e na sua vizinhança.

Contudo, é preciso salientar que cada construção possui particularidades. Portanto, as características de emissão de MP são alteradas de acordo com suas especificidades e, consequentemente, as intervenções devem ser estudadas caso a caso.

A seguir, são apresentadas algumas boas práticas em função das atividades, identificadas na literatura sobre o tema (BREEAM, 2009; GBC BRASIL, 2014; FUNDAÇÃO VANZOLINI, 2014).

\subsection{Atividades de Demolição}

As atividades de demolição podem ser praticadas de três formas distintas: a manual, a mecanizada e com a utilização de explosivos. Dentre elas, a manual é a mais indicada por emitir menor quantidade de MP em relação as demais.

Segundo EPA (1998), GLA (2005), Araújo e Cardoso (2007) e Resende (2007), algumas boas práticas podem ser adotadas durante a demolição, tais como:

a) Cercar a obra ou pontos de emissão com telas de poliéster de malha fina ou com chapas de madeira;

b) Remover os resíduos de demolição da obra o quanto antes, evitando sua exposição a ventos e chuvas. Quando a retirada não for possível, os resíduos devem ser cercados, umedecidos e cobertos;

c) Evitar atividades de demolição quando as velocidades do vento estiverem elevadas;

d) Manter a área umedecida após o término da demolição;

e) Aspergir água com mangueiras de alta vazão, antes e durante a atividade de demolição (Figura 1). 


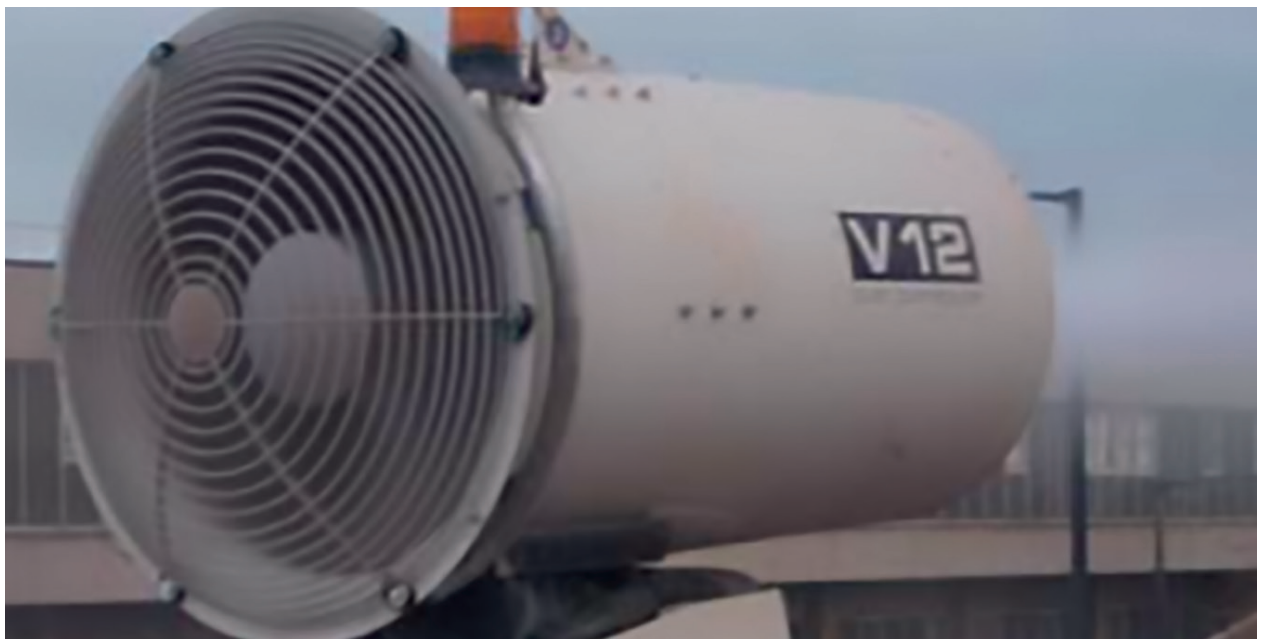

Figura 1 - Aspersão de água durante a demolição. Fonte: IAQM, 2016.

\subsection{Movimentação de Terra}

A emissão de MP nas atividades de movimentação de terra é muito significativa, sendo potencializada nos períodos de seca e ventos fortes. Tal emissão está ligada às atividades de corte e aterro, carga e descarga, movimentação de veículos e ao transporte de lama aderida aos pneus dos veículos.

Segundo EPA (1998), GLA (2005), Araújo e Cardoso (2007) e Resende (2007), as seguintes boas práticas podem ser adotadas para esta atividade:

a) Remover a vegetação existente conforme o avanço das atividades de movimentação de terra;

b) Evitar serviços de escavação durante períodos muito secos e com ventos fortes;

c) Realizar a remoção de terra da obra, preferencialmente, logo após sua escavação/movimentação;

d) Umedecer o solo periodicamente e prever barreiras físicas ao redor da obra ou das áreas de trabalho (Figura 2);

e) Manter as áreas em escavação umedecidas e cobertas nos períodos de paralisação;

f) Controlar a altura de lançamento de terra nos trabalhos de carga e descarga. É importante esvaziar a caçamba lentamente, evitando formação de nuvens de poeira;

g) Lavar os pneus dos veículos antes da saída dos canteiros (Figura 3). 


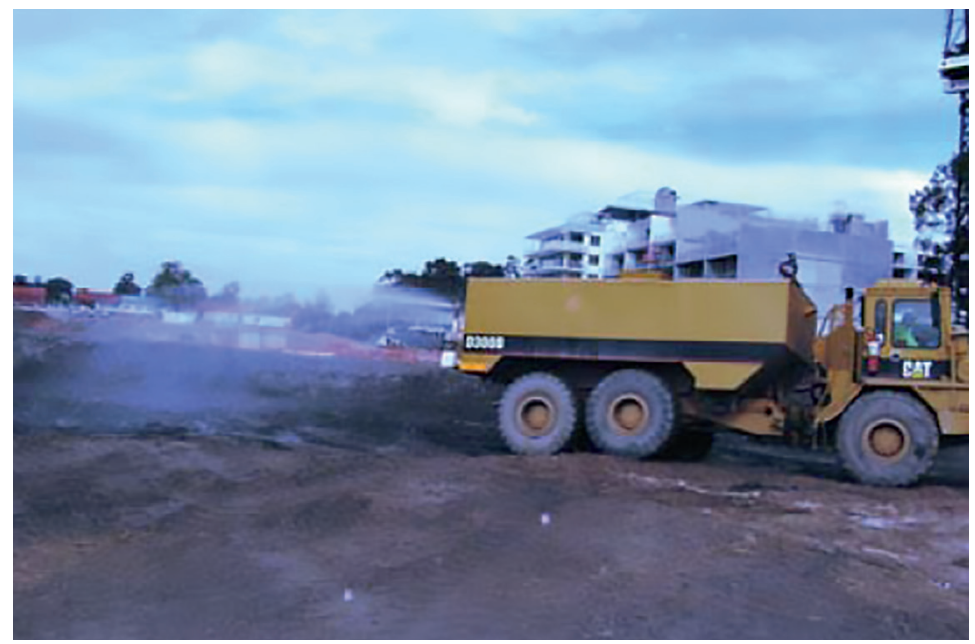

Figura 2 - Molhação durante a movimentação de terra. Fonte: Air Quality Guidance Note, 2016.

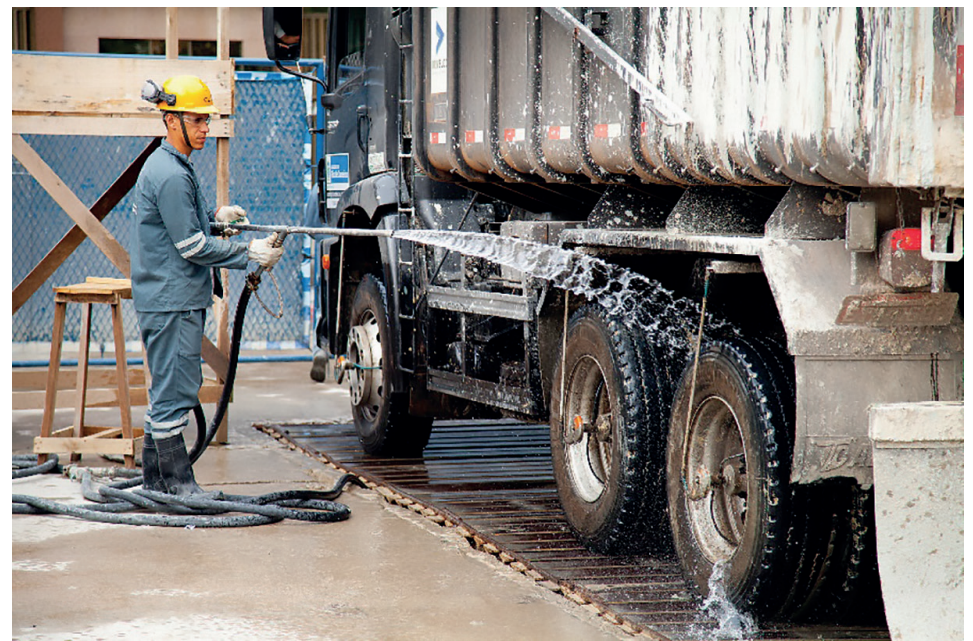

Figura 3 - Lavagem de pneus. Fonte: Revista CNT Transporte, 2016.

\subsection{Armazenamento}

Planejamento e gestão do sistema de armazenamento são importantes para otimização das áreas dos canteiros. Além disso, faz-se necessário que o armazenamento fique protegido da ação dos ventos e da chuva. O armazenamento inadequado de materiais também pode gerar emissão de MP na atmosfera. 
Segundo EPA (1998), GLA (2005), Araújo e Cardoso (2007) e Resende (2007), algumas boas práticas podem ser adotadas para armazenamento, como:

a) Manter os materiais e resíduos armazenados pelo menor período possível no canteiro;

b) Armazenar os materiais e resíduos protegidos da ação dos ventos e chuvas (Figura 4);

c) Manter as pilhas de materiais dispostas em condições que reduzam riscos de desmoronamentos;

d) Manter grandes pilhas de materiais e resíduos umedecidos constantemente, limitando a altura das pilhas a 2,50 metros;

e) Realizar limpezas periódicas dos locais de armazenamento;

f) Instalar exaustores com filtros, quando houver grande geração de MP no local de armazenamento;

g) Armazenar os materiais e resíduos longe das divisas e ambientes sensíveis ao MP (cursos d'água, hospitais, escolas, residências, locais com aglomerações de pessoas e outros);

h) Armazenar equipamentos de aspiração e limpeza para o caso de "vazamentos" acidentais.

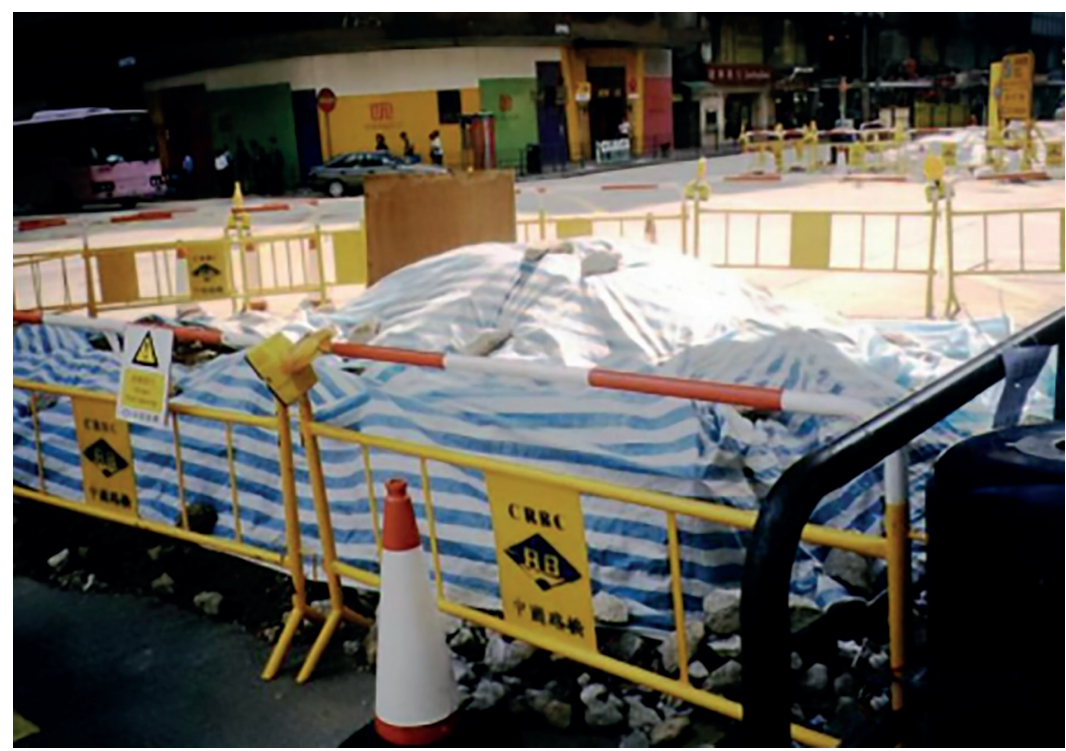

Figura 4 - Materiais armazenados protegidos da ação dos ventos e chuvas. Fonte: EPD Hong Kong, 2006. 


\subsection{Construção}

A variedade de atividades desenvolvidas dentro de um canteiro de obras faz com que, ao longo da execução da obra, sejam criadas fontes de emissão de material particulado de características diversificadas, sob vários aspectos, tais como: concentração produzida, tamanho das partículas, tempo de emissão, entre outros (RESENDE, 2007).

A avaliação das emissões do canteiro deve ser feita mediante a análise da sobreposição das diversas atividades desenvolvidas. Para tanto, o controle das emissões deverá ser feito por meio do conhecimento das características particulares de cada atividade.

Segundo EPA (1998), GLA (2005), Araújo e Cardoso (2007) e Resende (2007), algumas práticas podem minimizar a emissão de partículas em atividades construtivas:

a) Utilizar dispositivo de coleta de pó de serragem acoplado ao equipamento (Figura 5);

b) Utilizar serra manual acoplada à mangueira de água (Figura 5);

c) Realizar a atividade em ambiente com coifa exaustora e filtro, em caso de grande quantidade de emissões;

d) Fazer corte/perfuração em local protegido da ação dos ventos e dentro de caixote coletor;

e) Sempre que possível, evitar a produção de concreto e argamassas durante a execução da obra. Quando produzidos, fazê-los em local protegido da ação de ventos e chuvas;

f) Cobrir com lonas as misturas que forem deixadas de um dia para o outro;

g) Sempre que possível, evitar a realização de atividades que exijam desgaste superficial, substituindo a tecnologia construtiva;

h) Realizar varrição úmida ou aspiração com frequência;

i) Racionalizar o processo de produção de forma a diminuir a perda de argamassas e concretos por queda;

j) Verificar a estanqueidade dos equipamentos utilizados para transporte de concretos e argamassas;

k) Criar barreiras físicas de modo a evitar que as argamassas e concretos sejam lançados fora de um espaço controlável (telas nos andaimes fachadeiros, tapumes, lonas, entre outros) (Figura 6);

I) Evitar os serviços de queima, sempre que possível, nos canteiros de obra, pois lançam MP e gases;

m) Fazer a queima de materiais em incineradores públicos, quando for inevitável; 
n) Sempre que possível e necessário, realizar a escavação em partes, procurando manter a camada de proteção vegetal existente pelo maior tempo possível;

o) Compactar a superfície ou plantar vegetação, o mais breve possível, após o término dos serviços;

p) Utilizar barreiras físicas (tapumes, telas, lonas, entre outros) no contorno das áreas de serviço, evitando ou diminuindo a ação dos ventos e chuvas (Figura 6);

q) Desenvolver o planejamento físico da obra, procurando otimizar o tempo de duração desta atividade, para que, tão breve, as superfícies possam ser finalizadas;

r) Realizar a limpeza com a maior frequência possível para evitar o acúmulo de partículas.
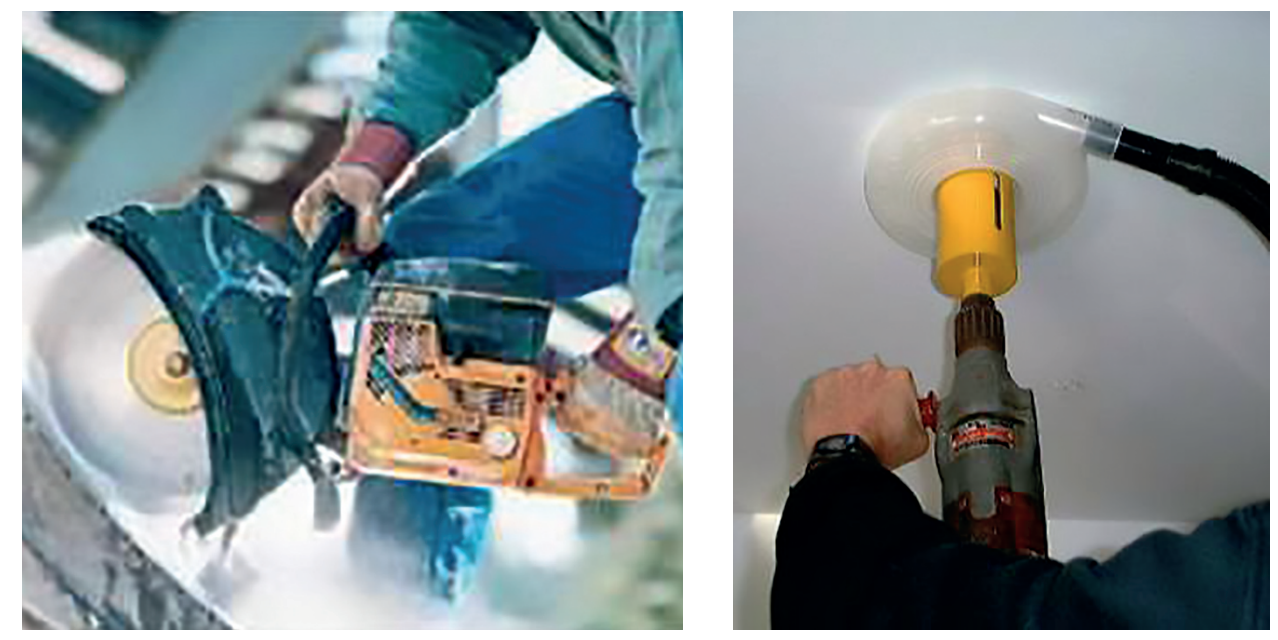

Figura 5 - Serra manual acoplada à mangueira de água e pefuratriz acoplada a sistema de coleta de pó. Fonte: www.contractorstools.com; www.dustmuzzle.com. Acesso em Nov. 2016.

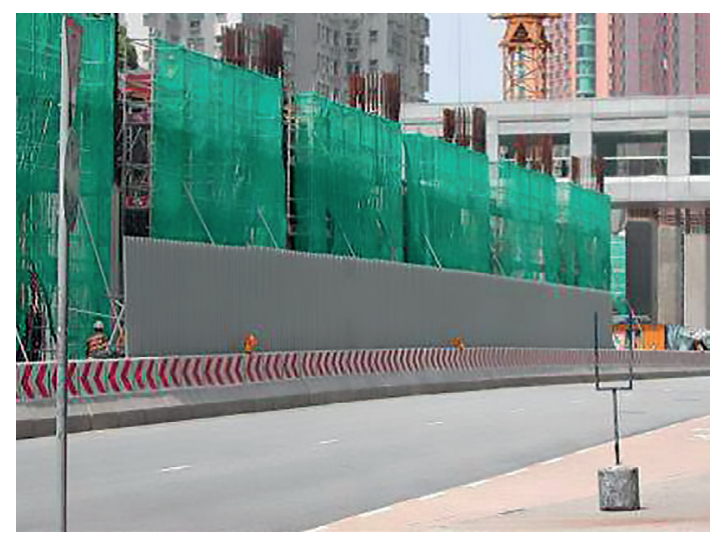

Figura 6 - Obra protegida com lona e andaimes fachadeiros. Fonte: EPD- Hong Kong, 2006. 
Vale salientar, que a eficácia e os resultados das medidas apresentadas, ainda que sejam preventivas, só podem ser garantidos a partir de uma continuidade cíclica de monitoramento durante toda a etapa de produção. É importante que o gestor da obra tenha o conhecimento adequado acerca de emissões de MP ou esteja amparado por profissional habilitado para que seja inserida a mitigação correta a cada atividade impactante.

\section{Conclusões}

O presente capítulo destacou a importância do controle e monitoramento das emissões de partículas provenientes dos canteiros de obra por meio das melhores práticas, com vista a proteger a saúde do trabalhador, da vizinhança da obra e do meio ambiente local. A geração de poeira pode ser substancialmente reduzida com a aplicação de técnicas cuidadosamente selecionadas de mitigação e gerenciamento eficaz da obra, uma vez que essas poeiras são difusas, tornando difícil o seu controle. O controle eficaz dessas emissões deve ser feito na sua fonte.

O controle da poeira pode mitigar alguns efeitos causados pela poluição, trazendo inúmeros benefícios tanto para os diferentes intervenientes da construção como para os construtores, por meio da melhor reputação empresarial com as autoridades reguladoras, além de proporcionar evoluções nas relações de trabalho com clientes, vizinhança e trabalhadores. Para a vizinhança e a comunidade, tal prática de controle possibilita menos interrupções na vida cotidiana, reduz os riscos para a saúde, além de diminuir os danos causados às propriedades. Já para o ambiente, pode reduzir a poluição do ar, água e os distúrbios provocados na fauna e flora existentes no entorno da edificação (LONDON COUNCILS, 2006).

O construtor deve ter como objetivo principal, portanto, não causar impactos no ambiente, o que impõe uma forte mudança na cultura hoje estabelecida pela construção civil e uma alteração nos sistemas construtivos existentes. Para que isso aconteça, é necessário reestudar os processos, visando estabelecer formas de evitar os impactos.

\section{Referências}

ARAÚJO, V.M; CARDOSO, F. Redução de impactos ambientais do canteiro de obras. Projeto Finep: Habitações mais sustentáveis. Finep. São Paulo, 2007.

ARAÚJO, I.P.S. Metodologia para Avaliação e Redução de Impactos Ambientais causados pela emissão de material particulado de canteiros de obras habitacionais com foco no impacto à vizinhança da obra. Dissertação (Mestrado) - Escola Politécnica de Salvador BA, 2014. 
ARAÚJO, I.P.S.; COSTA, D.B.; MORAES, R.J.B. Identification and Characterization of Particulate Matter Concentrations at Construction Jobsites. Sustainability (Basel), v. 6, p. 7666-7688, 2014.

BREEAM. Europe Commercial 2009 Assessor. Manual. BRE Global Ltd. 346p. 2009

CEQA. California Natural Resources Agency Guide. Construction Generated Criteria Air Pollutant and Precursor Emissions. CEQA 1-3. Farmington Hill, MI. 2009

CETESB. Companhia de Tecnologia de Saneamento Ambiental. Relatório da qualidade do ar de São Paulo. 2004. Disponível em: <http://www.cetesb.sp.gov.br>. Acesso em: abr. 2015.

CONAMA. Conselho Nacional do Meio Ambiente. 1990. Resolução conama $\mathrm{n}^{\circ} 003$. Disponível em: http:www.mma.conama.gov.br/conama. Acesso em: maio 2015.

COUNTESS ENVIRONMENTAL. 2006. WRAP fugitive dust handbook. Disponível em: http:// ulpeis.anl.gov/documents/dpeis/references/pdfs/Countess_Environmental_2006_ WRAP_Fugitive.pdf. Acesso em: set. 2015.

ENVIRONMENT AGENCY. Monitoring of particulate matter in ambient air around waste facilities. Technical Guidance Document (Monitoring) M17. Disponivel em: http:// www. environment-agency.gov.uk. Acesso em: mar. 2017.

ENVIRONMENTAL PROTECTION. The Air Quality Standards Regulations. 2010. Disponível em: http://www.legislation.gov.uk/uksi/2010/1001/pdf. Acesso em: jun. 2014.

EPA. Environmental Protection Agency. Characterization of buildingrelated construction and demolition debris in the United States Office of solidwaste. Estados Unidos, Junho de 1998. Reportn.o EPA 530-R-98-010.

EPD HONG KONG. Environmental Protection Department- Honk Kong. Air pollution control regulation relevant to the construction industry. Manual de treinamento da EPD - Hong Kong, 45p, 2006. Disponível em: http://www.epd-asg.gov.hk. Acesso em: nov. 2016.

LONDON COUNCILS. The Control of Dust and Emissions from Construction and Demolition - Best Practice Guidance. Londres: Greater London Authority, nov./ 2006.

GLA. Greater London Authority. The control of dust emissions from construction and demolition. Versão Draft London Best Practice Guide. London: Greater London authority e Association of London government, 2005.

GBC BRASIL. Green Building Council Brasil. Disponível em: http://www.gbcbrasil.org.br/ sistema/certificacao. Acesso em: ago. 2014.

IAQM. Institute Of Air Quality Management. Guidance on the Assessment of Dust from Demolition and Construction. Disponível em: http://www.iaqm.co.uk. Acesso em: Nov. 2016.

MARTINS, A. R. B. Caracterização e avaliação de poeiras presentes em canteiros de obras de edifícios verticais. Dissertação (Mestrado) - Escola Politécnica de Pernambuco. Recife, 2009. 
MUÑOZ, I.S.C.; PALACIOS, J.C.M. Gestiónen el control de emisionesdifusasenla actividad de la construcción. Universidad de Santiago de Chile, Facultad de Ingeniería. Santiago. 2001.

MORAES, R.J.B. Avaliação da emissão do material particulado proveniente de canteiros de obras habitacionais na fase de estrutura e alvenaria. Dissertação (Mestrado em Mestrado em Engenharia Ambiental Urbana) - Universidade Federal da Bahia, Bahia. 2015.

MORAES, R.J.B. ; COSTA, D. B.; ARAÚJO, I.P.S . Particulate matter concentration from construction sites focusing on concrete and masonry works. Journal of Environmental Engineering (New York, N.Y.), v. 1, p. 05016004-1, 2016.

PACYNA, J.M. The origin of artic air pollutants: lessons learned and future research. Science ofthe Total Environment, v. 160-161, p. 39-53, 1995.

MULESKI , G. E.; COWHERD, C. JR.; KINSEY, J. S. Particulate Emissions from Construction Activities. Journal of the Air \& Waste Management Association, 55:6, pp. 772-783, 2005.

RESENDE, F. Poluição atmosférica por emissão de material particulado: avaliação e controle nos canteiros de obras de edifícios. Dissertação (Mestrado) - Departamento de Engenharia de Construção Civil. Escola Politécnica, Universidade de São Paulo, São Paulo, 2007.

RESENDE, F.; CARDOSO, F. Gestão da emissão de material particulado no canteiro de obras de edifícios. V Simpósio Brasileiro de Gestão e Economia da Construção. Criação de Valor na Construção Civil: teoria e prática, Campinas, 2007.

US EPA. United States Environmental Protection Agency. Particle pollution and your health. Estados Unidos: US EPA, 2006. 2p.

\section{Sites consultados}

AIR QUALITY GUIDANCE NOTE. Disponível em: http://www.epa.nsw.gov.au. Acesso em: nov. 2016.

FUNDAÇÃO VANZOLINI. Disponível em: http://www.vanzolini.org.br. Acesso em: maio 2014.

Guidance on the Assessment of Dust from Demolition and Construction. Disponivel em: http://www.iaqm.co.uk. Acesso em: nov. 2016.

Revista CNT Transporte. Disponível em: http://www.cnt.org.br/Paginas/revista-cnttransporte-atual. Acesso em: nov. 2016.

http://www. contractorstools.com. Acesso em: nov. 2016.

http://www.dustmuzzle.com. Acesso em: nov. 2016 
